\title{
Dominant Factors Affecting Regional Inequality of Infant Mortality in Vietnam: A Structural Equation Modelling Analysis
}

\author{
Mai P. Nguyen ${ }^{1,2^{*}}$, Chi M. Nguyen ${ }^{3}(\mathbb{0}$
}

\begin{abstract}
Background: Despite Vietnam's acclaiming achievements of reducing overall infant mortality rate (IMR), the IMR decline does not occur equally in all regions in Vietnam. This study aims to investigate dominant factors that affect the inequality of infant mortality across regions in Vietnam during the period 2005-2015.

Methods: We use nationally representative data to construct a panel data of 6 economic regions in Vietnam from 2005 to 2015. We employ the structural equation modelling (SEM) approach to quantify the causal effect of socio-economic status (SES), accessing to skilled birth attendance (SBA) and other relevant factors on the disparity of IMR across regions. Results: SES, which is measured by 3 indicators - illiteracy rate (IR), poverty rate (PR) and income per capita - is the dominant factor causing regional inequalities of infant mortality, followed by the use of SBA. Among these indicators, the PR is the most important one causing the regional disparity of IMR and accessing to SBA. The total effect of SES on infant mortality disparity is 2.6 times as high as that of accessing skilled healthcare personnel.

Conclusion: Bridging the regional gap of using skilled health personnel would contribute to improving the infant mortality inequality in Vietnam. This inequality, however, is not significantly improved only with medical interventions but also with broader and more comprehensive socio-economic interventions at both national and regional levels. Our findings confirm that poverty reduction and growth strategies should be the main focus to boost medical interventions and improve IMR all over the country.

Keywords: Infant Mortality, Regional Inequality, Skill Birth Attendance, Socio-Economic Status, Vietnam Copyright: @ 2021 The Author(s); Published by Kerman University of Medical Sciences. This is an open-access article distributed under the terms of the Creative Commons Attribution License (https://creativecommons.org/licenses/ by/4.0), which permits unrestricted use, distribution, and reproduction in any medium, provided the original work is properly cited.

Citation: Nguyen MP, Nguyen CM. Dominant factors affecting regional inequality of infant mortality in Vietnam: a structural equation modelling analysis. Int J Health Policy Manag. 2021;10(8):475-482. doi:10.34172/ijhpm.2020.59
\end{abstract}

\section{Article History:}

Received: 29 August 2019

Accepted: 14 April 2020

ePublished: 29 April 2020

\section{Key Messages}

Implications for policy makers

- The findings would be evidence-based for both the medical interventions and poverty reduction interventions at regional and national levels in Vietnam. They would be of interest of policy-makers, healthcare providers and international organizations who are working hard in improving mother and child's health and addressing health's inequity in Vietnam.

- The case of Vietnam would provide the World Health Organization (WHO) more evidence of the infant mortality disparity within a country, which in turn would inform WHO in setting guidelines and definitions and framework to support low- and middle-income countries (LMICs) to obtain 2030 Sustainable Development Goals (SDGs).

Implications for the public

The poverty rate (PR) in Asia countries is significantly affecting the infant mortality inequality and highlighted in the World Mortality Report 2015 by the United Nations, using national Health Demographic Surveys with no data of Vietnam. This study, therefore, contributes another evidence from Vietnam to strengthen the United Nations' conclusions. More importantly, the poverty plays a critical role in not only the inequality of infant mortality rate (IMR) but also the regional disparity of accessing to skilled birth attendance (SBA) in Vietnam. Finally, the study employs structural equation modelling (SEM) to model a system of causal relationships among all related factors that would be applicable in other countries with similar socio-economic conditions.

\section{Background}

Vietnam achieved a significant reduction of infant mortality rate (IMR) over the period 1990-2015, from 44.1 per 1000 live births in 1990 to 14.7 in 2015 . However, the decline does not take place equally in all regions of the country. The highest mortality rates are seen in mountainous and underprivileged regions at 24.8 per 1000 live births, which is nearly 3 times as high as the rate in the most affluent area at 8.6 per 1000 live births, and nearly 2 times the overall country's IMR in $2015 .{ }^{1}$ The disparity between wealthy and disadvantaged areas tends 
to persist over time.

Vietnam is divided into 6 economic regions, ie, Red River Delta, Northern Midlands and Mountainous areas, North Central and Central Coastal areas, Central Highlands, Southeast area, and Mekong River Delta. These 6 regions differ significantly in terms of demographics, speed and level of their socio-economic developments. The Southeast area with a high annual income per capita, a high literacy rate and a low poverty rate (PR), has the best socio-economic status (SES), followed by the Red River Delta. Meanwhile, the Northern Midlands and Mountainous area has the lowest SES compared to other regions.

In addition to SES, the proportion of births attended by skilled health personnel (so-called the skilled birth attendance, SBA) is one of the key factors affecting the IMR, thus a benchmark to assessing the progress towards the targets of reducing IMR in low- and middle-income countries (LMICs). ${ }^{2}$ SBA is critical medical services to women and their newborns during pregnancy, childbirth and the postpartum period, contributing to the reduction of preventable causes of neonatal death of newborn babies such as birth asphyxia and severe infections in Vietnam. ${ }^{3}$ This proportion of SBA is significantly different among economic regions in Vietnam. For instance, it is varying from $100 \%$ in the Red River Delta to only $91 \%$ in Northern Midlands and Mountainous areas and 94.8\% in Central Highlands. ${ }^{4}$

The huge gap of IMR among different economic regions has drawn a great deal of attention from policy-makers, healthcare providers, international donors and researchers in Vietnam. Particularly, the Vietnamese government report on the achievements of Millennium Development Goals has highlighted medical interventions such as SBA, vaccinations and family planning as major contributors to reduce the IMR. ${ }^{5}$ In a number of earlier studies, SES has been identified as the determinant of the use of SBA in Vietnam. ${ }^{6,7}$ In separate studies, SES also shows a strong relationship with the IMR. ${ }^{8,9}$ However, to our knowledge, no research considers these factors' linkages as a systematic structure that affects the inequality in SBA and IMR simultaneously across economic regions in Vietnam.

As the goals of Vietnamese government is to bridge the gap of IMR among economic regions to move forward to Sustainable Development Goals (SDGs) in 2030, ${ }^{10}$ there is a need to advance understandings on which factors are dominant, and how they contribute to this disparity. In particular, we need to examine the pathways through which the determinants of IMR such as SES, SBA, vaccinations and other relevant factors are interrelated in a system of causal relationships and at varying levels of magnitude. This study, using structural equation modelling (SEM) analysis, can shed lights on those pathways to infant mortality inequality over the period 2005-2015 in Vietnam.

This study makes several contributions to the current literature and practice. First, it provides evidence of the determinants to reducing infant mortality inequality among regions of Vietnam. The findings would be of interest of policy-makers, healthcare providers and international organizations who are working hard in improving mother and child's health and addressing health's inequity in Vietnam. Second, it uses SEM to model a system of causal relationships among all related factors that would be applicable in other countries with similar socio-economic conditions. Finally, the case of Vietnam provides the World Health Organization (WHO) more evidence of the infant mortality disparity within countries, which in turn would inform WHO in setting guidelines, definitions and framework to support LMICs to obtain 2030 SDGs.

\section{Methods \\ Data Construction and Sources}

In this study, we analyze data of 6 economic regions from 2005 to 2015 to identify the main factors affecting infant mortality across regions in Vietnam. In each economic region, we collected IMR indicators and medical interventions factors (SBA rate, vaccination rate), population growth (total fertility rate, TFR) and socio-economic factors (ie, PR, income per capita, and illiteracy rate [IR] as a basic level of education) other relevant indicators. All indicators are observed over 11 years. Therefore, the dataset contains a tally of 66 observations, The medical intervention indicators are collected from the annual Statistics Health Yearbooks of the Vietnam's Ministry of Health $(\mathrm{MoH}) .{ }^{4}$ Meanwhile, the IMR, population growth and other socio-economic factors are sourced from Vietnam's national statistical agency, so-called the General Statistics Office (GSO) of Vietnam which provides authentic official and nationally representative statistics on a wide range of economic, social, population and environmental issues. The IMR, population growth and other socio-economic factors are collected through household surveys of which samples are selected in the way to represent regions, provinces/cities and the entire country. ${ }^{1}$

\section{Variables of Interest}

We use the IMR of the 6 economic regions over 11 years as the dependent variable, and the others as the explanatory variables that include SES, the rate of non-fully vaccination, the proportion of SBA, and the TFR. The selection of explanatory variables is based on the literature and the availability of data in the Vietnamese context. ${ }^{10}$

SES has been well known as an important factor that determines the IMR in both LMIC and high-income countries. ${ }^{11,12}$ In this study, annual income per capita, PR and IR are used as proxies for SES. The income per capita captures the level of average income across regions. It however does not capture individual income, therefore, can mask disparities among individuals' income. This indicator is estimated on a logarithmic scale because on such a scale, equal distances between income ranges represent equal percentage changes. For example, the distance between $\$ 500$ and $\$ 1000$ (a 100\% change) is the same as the distance between $\$ 1000$ and $\$ 2000$ (a 100\% change). The PR describes the distribution of low income across regions. The higher rate of poverty and illiteracy are expected to lead to a higher IMR. ${ }^{13}$ We believe that these SES variables are informative to roughly depict differences of regional socio-economic conditions and to examine its effect on IMR. 
For the other explanatory variables, vaccinations and SBA have been reported as key medical interventions contributable to the decrease of infant mortality in Vietnam. ${ }^{5}$ In this study, we hypothesize that those interventions directly affect IMR.

The TFR is an element of population growth, reflecting both the causes and effects of economic and social developments. It also reflects the varying demand for infant professional healthcare. In response, skilled birth personnel need to adjust accordingly to the TFR. We, therefore, model the TFR as an input to the rate of SBA. ${ }^{2,5}$

The definition and measurement of our dependent and explanatory variables are presented in Table 1.

\section{Data Analysis Using Structural Equation Modelling}

SEM is a multivariate statistical analysis technique that is used to construct and analyze structural relationships between measured variables and latent factors with a system of linear equations. This modelling technique allows us to track not only the direct effects but also the indirect ones of each variable to the dependent variable,$^{15}$ in our study, ie, IMR. A pathway diagram, which is a flowchart showing variables interconnected with lines indicating causal flows to the dependent variable, present the structure and outcome of this analysis.

We hypothesize that besides the direct effect on IMR, the SES also affects the IMR through 2 indirect ways: the proportion of SBA and the non-fully vaccination rate. Those 2 latter variables, in turn, have direct effects on the IMR. As SES is not easily observable, we build a simple proxy for SES that is a common latent factor of 3 socio-economic measures, ie, IR, PR and log of income per capita. Hereinafter, we name this common latent factor as SES_lat. Figure 1 presented 6 economic regions in Vietnam and their estimated average SES_lat during the period 2005-2015.

Figure 2 illustrates the hypothesized model demonstrating causal flows from our groups of explanatory variables (SES, medical intervention, and population growth) to the IMR. Lines with arrows represent the directional links among variables.

To test this hypothesis, we first estimate the latent factor of SES across regions by applying a maximum likelihood factor analysis to 3 highly correlated variables, ie, IR, PR and log of per capita income, as what follows:

$I R=S E S \_l a t+\varepsilon_{1}$

$P R=\alpha$ SES_lat $+\varepsilon_{2}$

$L O G \_I N C=\beta S E S \_l a t+\varepsilon_{3}$

As clearly seen, the common factor SES_lat is based on the $I R$, thus representing an unfavourable socio-economic indicator of each region. That means higher SES_lat implies a lower SES. As a result, SES_lat has a positive effect on $P R$, and negative effect on the log of income.

We then use this estimated latent SES indicator to investigate its intertwined relationship with IMR and other factors. We start with a simple random effect model, where 2 separate linear relationships are estimated as follows:

$$
\begin{aligned}
& I M R_{i, t}=a_{1}+b_{1} S B A_{i, t}+c_{1} N O N_{V A C_{i, t}}+e_{1, i, t} \\
& S B A_{i, t}=a_{2}+b_{2} S E S_{-} l a t_{i, t}+c_{2} T_{F} R_{i, t}+e_{2, i, t}
\end{aligned}
$$

where $i$ and $t$ indicate region $i$ at year $t$, and $\left(e_{1}, e_{2}\right)$ are residuals. In this set-up, SES affects IMR indirectly through the SBA channel. As our sample size is small, we use bootstrap with 100 replications to obtain the statistics for all estimated models.

This simple model shows that there is a significant impact of SES on SBA, as well as SBA on IMR. However, the BreuschPagan Lagrangian tests for random effect of these 2 equations indicate that the residuals may have different random effects

\begin{tabular}{|c|c|c|c|c|}
\hline Variables & Unit & Label & Measurements & Sources \\
\hline \multicolumn{5}{|l|}{ Dependent } \\
\hline IMR & Permille (per thousand) & IMR & The number of deaths under 1 year of age per 1000 live births & Vietnam GSO \\
\hline \multicolumn{5}{|l|}{ Explanatory } \\
\hline The rate of SBA & Percentage & SBA & The proportion of births delivered by skilled birth attendants & Vietnam MoH \\
\hline $\begin{array}{l}\text { The rate of non-fully } \\
\text { vaccination }\end{array}$ & Percentage & NON_VAC & The rate of infants under 1 year is not fully vaccinated against 10 diseases & Vietnam MoH \\
\hline TFR & Percentage & TFR & $\begin{array}{l}\text { The average number of live births of a woman that would have during her } \\
\text { whole life if during her reproductive period her age-specific fertility rates } \\
\text { were similar to that observed in the reference period, usually the last } 12 \\
\text { months prior to the survey }\end{array}$ & Vietnam GSO \\
\hline $\begin{array}{l}\text { The income per capita } \\
\text { on a logarithmic scale }\end{array}$ & Million VND & LOG_INC & Total income of households in reference year divided by their headcounts & Vietnam GSO \\
\hline PR & Percentage & PR & $\begin{array}{l}\text { The proportion of the population living below the poverty lines calculated by } \\
\text { the GSO and the World Bank based on consumption. Details of the methods } \\
\text { of calculations can be found at World Bank documents }{ }^{14}\end{array}$ & Vietnam GSO \\
\hline Adult IR & Percentage & IR & $\begin{array}{l}\text { The proportion of illiteracy persons aged over } 15 \text { over the population aged } \\
\text { over } 15\end{array}$ & Vietnam GSO \\
\hline
\end{tabular}

Table 1. Definition and Measurements of Variables

Abbreviations: SBA, skilled birth attendance; TFR, total fertility rate; GSO, General Statistics Office; MoH, Ministry of Health; PR, poverty rate; IR, illiteracy rate; IMR, infant mortality rate. 


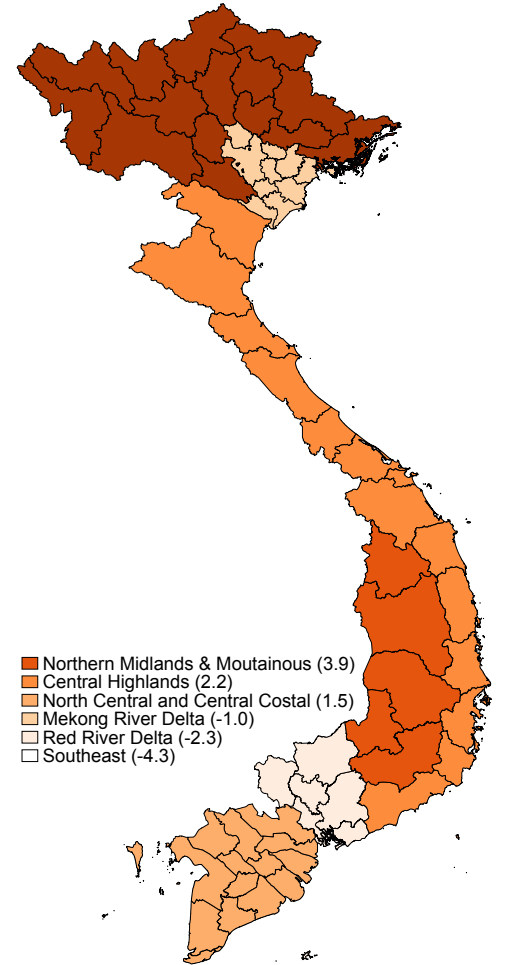

Figure 1. Six economic regions in Vietnam and their estimated average SES_ lat during the period 2005-2015.

The average SES lat is simply the annual average of our estimated latent SES over the period 2005-2015 in each region. The higher is SES_lat, the higher rates of illiteracy and poverty are. Thus, the regions in darker (alerting) orange color are the ones with more socio-economic disadvantage. The map is built using GIS from the Database of Global Administrative Areas (GADM).

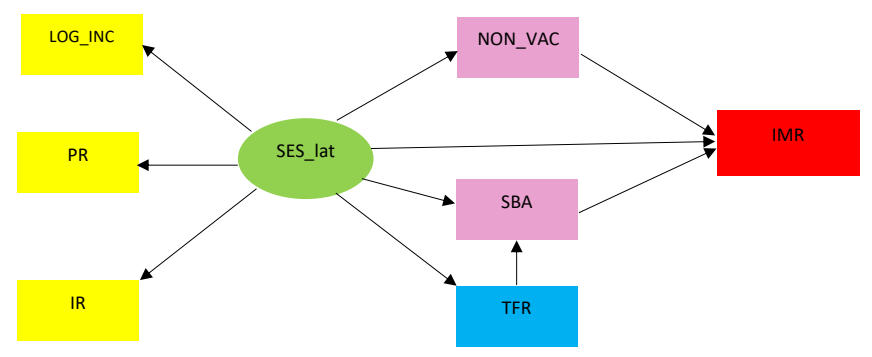

Figure 2. The Hypothesized Model of Inter-correlation Among SES, Medical Intervention, Population Growth, and IMR.

Abbreviations: SBA, skilled birth attendance; TFR, total fertility rate; PR, poverty rate; IR, illiteracy rate; IMR, infant mortality rate; SES, socio-economic status.

across regions, thereby using this pooled OLS is not adequate (see Supplementary file 1 for more details). We, therefore, proceed to our SEM which can provide a better understanding.

Our system of linear relationships in SEM is represented by

$$
\begin{aligned}
& I M R_{i, t}=a_{7}+b_{7} S E S_{\text {lat }_{i, t}}+c_{7} S B A_{i, t}+d_{7} N O N_{V A C_{i, t}} \\
& +e_{7} T F R_{i, t}+\varepsilon_{7, i, t} \\
& T F R_{i, t}=a_{6}+b_{6} S E S_{\text {lat }_{i, t}}+\varepsilon_{6, i, t} \\
& S B A_{i, t}=a_{5}+b_{5} S E S_{l a t}{ }_{i, t}+T F R_{i, t}+\varepsilon_{5, i, t} \\
& N O N \_V A C_{i, t}=a_{4}+b_{-} 4 S E S \_l a t_{i, t}+\varepsilon_{4, i, t}
\end{aligned}
$$

where $\left(\varepsilon_{4}, \varepsilon_{5}, \varepsilon_{6}, \varepsilon_{7}\right)$ are iid random residuals. In this model, the latent variable, SES_lat, affects IMR not directly but indirectly through influencing vaccination rate, SBA, and TFR. Given our small sample size, we apply a bootstrap method to make statistical inference, which basically builds an empirical distribution for a statistic by resampling the available data appropriately. The indirect and direct effects of explanatory variables on the IMR are estimated, and the causal relationships between variables are graphed in a pathway diagram (see the result section for more details).

Specification tests: The goodness of fit of the 2 first random effect models are assessed by Breusch and Pagan Lagrangian test. The goodness of fit of SEM at overall and equation level is conducted to evaluate if the hypothesized model reflects the observed data and how much of the variance of explanatory variables is being explained by the model. We report 4 statistics of the model fitness - the model chisquare, comparative fit index (CFI), root mean square error of approximation (RMSEA) and standardized root mean square residual (SRMR). ${ }^{16,17}$

It should be noted that this study does not seek to infer to individuals' preferences by using regional data, therefore, it is not subject to an ecological fallacy. ${ }^{18}$

Results

Overview of IMR and SBA Over the Period 2005-2015

As shown in Figure 3, the regional IMR was gradually decreasing during the period 2005-2015. The disparity among economic regions, however, was still unchanged and huge, especially between low SES regions such as Central Highlands, Northern Midlands and Mountainous areas, and high SES areas such as Red River Delta and Southeast region. The biggest IMR gap during the time was nearly $17 \%$.

Figure 4 demonstrates the upward trend of the proportion of SBA. The most interesting aspect of this trend is that the gap in the proportion of SBA has been gradually bridged among economic regions. However, the proportion of SBA has been still lower in Central Highlands, Northern Midlands and Mountainous areas, as compared to Red River Delta and Southeast regions.

Descriptive Statistics of Independent and Explanatory Variables by Regions, 2005-2015

Table 2 compares the summary statistics of IMR and explanatory variables among 6 economic regions. What stands out in the table is that Central Highlands and Northern Midlands \& Mountainous areas are regions with the lowest socio-economic indicators and proportion of SBA; the highest TFR and IMR. In terms of immunization coverage, although Central Highlands has the highest non-fully coverage rate of $8.97 \%$, this rate is not much different as compared with the Southeast region at $6.53 \%$.

Estimated Direct, Indirect and Total Effects of Explanatory Variables on IMR

Table 3 illustrates the effect of income, PR and IR on SES_lat. An increase in this unfavorable SES_lat indicator triggers a $1 \%$ increase in IR, approximately $2.76 \%$ increase in the $P R$, 


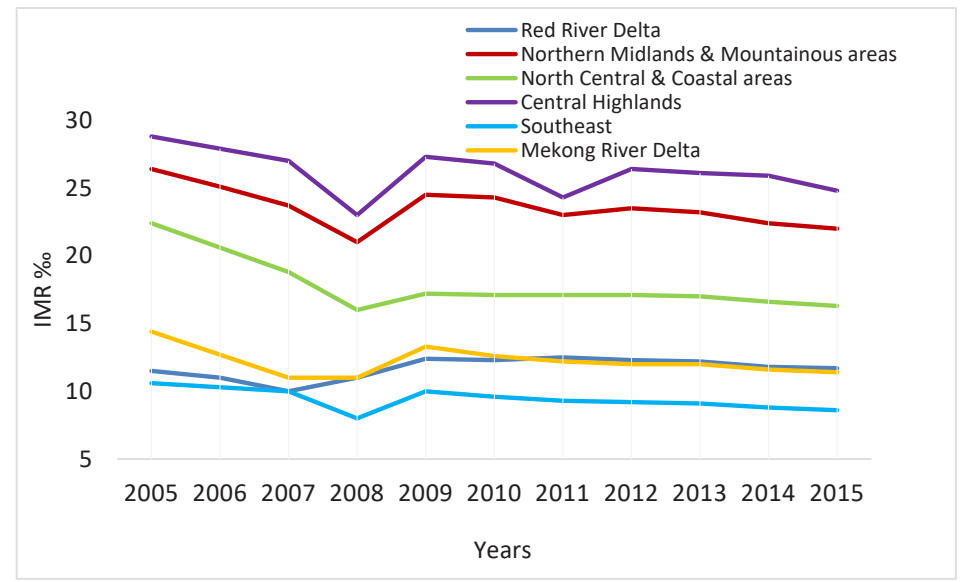

Figure 3. The Trend of IMR by Economic Regions in Vietnam. Abbreviation: IMR, infant mortality rate.

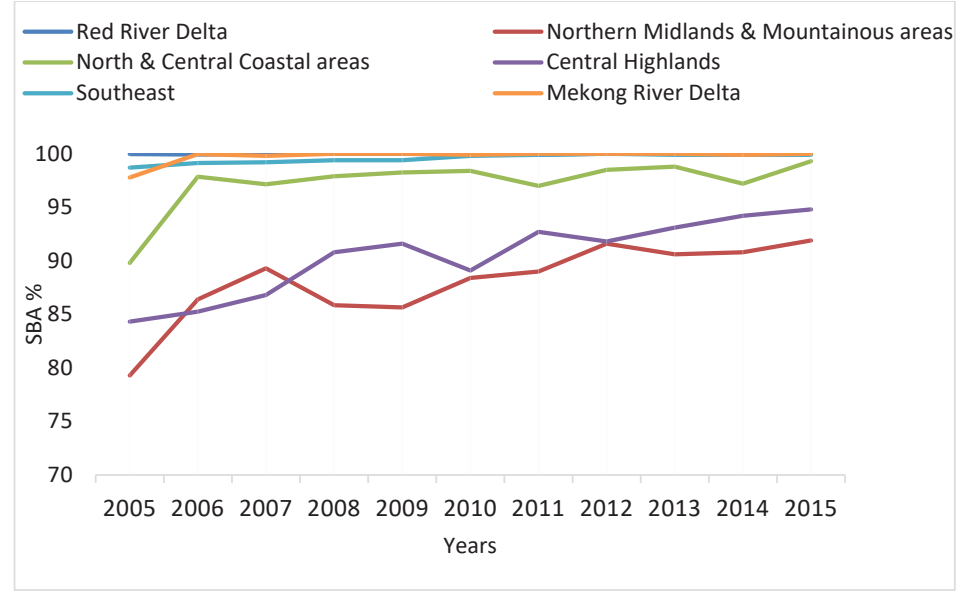

Figure 4. The Trend of SBA by Economic Regions in Vietnam. Abbreviation: SBA, skilled birth attendance.

and a $0.12 \%$ decrease in income.

Our estimated indirect and direct effects of explanatory variables on IMR are presented in Table 4 . We find that 2 dominant factors contributing to reducing IMR during the period are SES (ie, SES, which is opposite to the SES_lat) and SBA. Of those, the total effect of SES on IMR is 2.6 times as high as the effect of SBA on IMR. This notably larger effect of SES on IMR is due to its magnified influence through the indirect pathway, reducing the TFR and the non-vaccination rate while boosting the SBA rate.

The inter-relationships among variables are graphed in Figure 5. The arrows show the directional and causal pathways among variables within the model. Numbers alongside the arrows represent the coefficients of causal variables to their dependent variables. The small circles with epsilon from 1-7 indicate unique error terms of the system that also randomly effect our variables of interest. For example, besides SES_lat, other random factors such as transportation condition and

Table 2. Means and Standard Deviations of Independent and Explanatory Variables by Economic Regions in Vietnam

\begin{tabular}{|c|c|c|c|c|c|c|}
\hline Variable & $\begin{array}{l}\text { Red River } \\
\text { Delta }\end{array}$ & $\begin{array}{c}\text { Northern Midlands \& } \\
\text { Mountainous Areas }\end{array}$ & $\begin{array}{c}\text { North Central \& Central } \\
\text { Coastal areas }\end{array}$ & Central Highlands & Southeast & Mekong River Delta \\
\hline IMR & $11.7(0.78)$ & $23.55(1.51)$ & $17.84(1.98)$ & $26.21(1.67)$ & $9.41(0.78)$ & $12.20(1.02)$ \\
\hline SBA & $99.97(0.04)$ & $88.07(3.66)$ & 97.29 (2.59) & $90.41(3.58)$ & $99.57(0.43)$ & $99.58(0.85)$ \\
\hline NON_VAC & $3.95(5.55)$ & $5.39(2.48)$ & $7.10(6.68)$ & 8.97 (10.59) & $6.53(4.00)$ & $5.42(2.98)$ \\
\hline TFR & $2.12(0.08)$ & $2.32(0.16)$ & $2.29(0.06)$ & $2.62(0.25)$ & $1.70(0.10)$ & $1.87(0.07)$ \\
\hline LOG_INC & $2.42(0.35)$ & $1.87(0.26)$ & $2.00(0.29)$ & $2.07(0.27)$ & $2.8(0.22)$ & $2.21(0.25)$ \\
\hline$P R$ & $7.52(2.83)$ & $24.72(4.36)$ & $18.05(4.67)$ & $20.04(5.02)$ & $2.15(1.15)$ & $11.09(2.50)$ \\
\hline IR & $2.96(1.09)$ & $12.69(2.26)$ & $6.20(0.97)$ & $10.89(2.07)$ & $4.49(1.73)$ & $8.50(1.62)$ \\
\hline
\end{tabular}

Abbreviations: SBA, skilled birth attendance; TFR, total fertility rate; PR, poverty rate; IR, illiteracy rate; IMR, infant mortality rate.

Note: The number in parentheses is the standard deviation. 
Table 3. Effect of Income, Poverty Rate and Illiteracy Rate on SES_lat

\begin{tabular}{lccc}
\hline Variable & Estimated Coefficient & Standard Error & $\mathbf{9 5 \%} \mathbf{C l}$ \\
\hline IR & Reference & & \\
LOG_INC & $-0.12^{* *}$ & 0.03 & $(-0.18,-0.06)$ \\
PR & $2.76^{* *}$ & 0.53 & $(1.71,3.81)$ \\
\hline
\end{tabular}

Abbreviations: $P R$, poverty rate; IR, illiteracy rate.

${ }^{* *} P<.01$.

Table 4. Effect of Explanatory Variables on IMR

\begin{tabular}{lccc}
\hline Variable & Direct Effect & Indirect Effect & Total Effect \\
\hline IMR & & & \\
SES_lat & $0.88^{* *}$ & $0.77^{* *}$ & $1.65^{* *}$ \\
SBA & $-0.63^{* *}$ & NA & $-0.63^{* *}$ \\
NON_VAC & 0.05 & NA & 0.05 \\
TFR & NA & 1.85 & 1.85 \\
SBA & & & \\
SES_lat & $-1.44^{* *}$ & NA & $-1.44^{* *}$ \\
TFR & $-2.92^{*}$ & NA & $-2.92^{*}$ \\
NON_VAC & & & \\
SES_lat & 0.27 & NA & 0.27 \\
TFR & & & \\
\hline SES_lat & $0.08^{* *}$ & NA & $0.08^{*}$ \\
\hline
\end{tabular}

Abbreviations: SBA, skilled birth attendance; TFR, total fertility rate; IMR, infant mortality rate.

${ }^{*} P<.05,{ }^{* *} P<.01$

religious diversity also affect the use of SBA, and included in a random error $\varepsilon_{5}$.

The specification tests for the goodness of fit yields $\chi^{2}$ $=32.09, \quad P<.01 ; \quad \mathrm{CFI}=0.90 ; \quad \mathrm{SRMR}=0.04 ; \quad \mathrm{RMSEA}=0.32$. All standardized residual co-variances are less than 0.37 . Although the chi-square and RMSEA are not within the cutoff good fit (see Supplementary file 2 for more details) because of the small sample size of this study, the other indices, CFI and SRMR, show that the model fits well to the data.

Overall, the results indicate that SES has causal relationships with IMR and SBA. The direct effect of SES on IMR is higher than the direct effect of SBA on IMR. In addition, SES also has an indirect effect on IMR through the SBA. Among the 3 indicators that measure the SES, the PR is the most important factor linked to the regional gap of SBA and IMR.

\section{Discussion}

Although a steady upward trend in SES and in the access of SBA, together with a downward trend in IMR has been observed in all economic regions in Vietnam, the regional gap of infant mortality remains unchanged. This study provides evidence to explain this infant mortality inequality. It also goes beyond simply demonstrating the linear relationship among IMR and its predictors to understand the pathway through which these predictors are interrelated in a set of linear and causal relationships.

SES is at the center of driving the disparity of IMR across the country. It has both indirect and direct effects on IMR. The direct effect on IMR is consistent with findings in a large number of studies and reviews that have highlighted SES as the critical determinant of infant mortality. ${ }^{19-22}$ The PR significantly affects the infant mortality inequality in Asia countries is also highlighted in the World Mortality Report 2015 published by the United Nations using national Health Demographic Surveys. Vietnam case, unfortunately, is not covered in this analysis. Therefore, this study strengthens the conclusions by adding up more evidence from Vietnam. ${ }^{23}$ Moreover, it further support the views of the indirect effect of SES on IMR through SBA is also similar to findings by Afulani and Moyer in Ghana. ${ }^{24}$

Although all 3 SES indicators have direct and indirect effects on IMR, the PR has a stronger effect on the IMR and SBA than the income per capita and IR. This finding has an important implication for interventions that emphasizing the reduction of regional PR would be more likely to bridge the regional gap in IMR. Therefore, medical interventions should equally align with the implementation of the comprehensive poverty reduction and growth strategy across the country.

The proportion of SBA has a direct effect on the IMR, but it is also being affected by SES. This finding reflects 2 important issues of service users and providers in Vietnam. In terms of providers, the quantity, quality and distribution of skilled birth attendants have not been equally placed among economic regions. ${ }^{25}$ Given the regions with low SES have difficulties in attracting and retaining highly skilled health workers, the

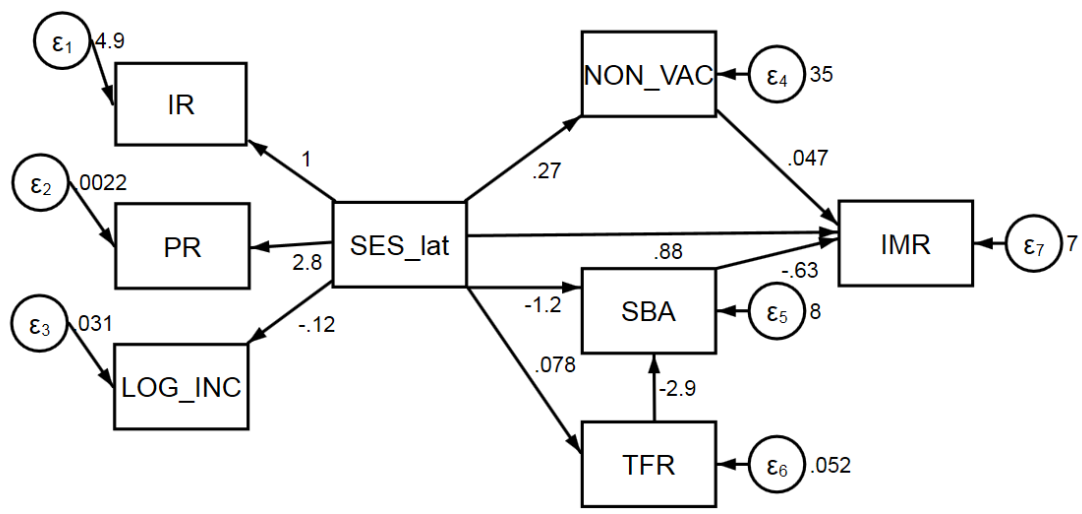

Figure 5. Pathway Diagram Representing the Major Drivers of Infant Mortality Inequality in Vietnam. Abbreviations: TFR, total fertility rate; PR, poverty rate; IR, illiteracy rate; IMR, infant mortality rate. 
quality of SBA is not homogeneous among regions. Therefore, the variation of quality of SBA of regions should be taken into account since the competence of SBA is playing a critical role to the reduction of IMR. ${ }^{26}$ This appreciates the WHO's effort to provide a new definition of $\mathrm{SBA}^{2}$ to address the disparity in quality of SBA. In terms of users, inequality of using maternal healthcare, including SBA is frequently due to contextual issues. ${ }^{27}$ In Vietnam, the income per capita, education and beliefs are most likely the barriers for an ethnic minority group of women, most of them live in Northern Midlands and Centre Highlands, to use birth support services. Moreover, language is also a barrier for midwives to reach out and support these ethnic women. ${ }^{28}$

Unlike other studies in LMICs, ${ }^{29,30}$ the full vaccination coverage does not statistically significant affect regional IMR in Vietnam. Furthermore, the SES is not statistically significantly associated with the vaccination coverage rate. Vietnamese contextual reasons would explain this finding. Firstly, the National Expanded Program of Immunization since 1981 has been successfully implemented. It does not just provide free vaccinations for infants in the whole country, but also especially focus on targeting infants living in disadvantaged areas. ${ }^{31}$ Secondly, the coverage rate is now substantially high in all regions; therefore, the community immunity or herd immunity - which give protection to a community where the disease cannot spread - has occurred. ${ }^{32}$ Lastly, many of the vaccinations are the first dose, and need following up in later years. Thus, vaccinations may have long term effects, and not reveal significantly in the first year of life.

In conclusion, SES and SBA are the main factors affecting regional inequality of infant mortality in Vietnam. Closing the gap of SBA would contribute to improving the infant mortality inequality. More importantly, SES, in particularly the poverty, play a critical role in not only the inequality of IMR but also the regional disparity of accessing to SBA in Vietnam. Therefore, addressing this inequality cannot be done only within the healthcare system but in a broader socio-economic context. It requires more comprehensive interventions at national poverty reduction and growth strategy all over the country. The case of Vietnam raises an issue that infant mortality disparity within a country should be considered and factored in when setting and assessing the SDGs. This suggests WHO promote more evidence of the infant mortality disparity within countries which would inform WHO in setting guidelines and definitions and framework to support LMICs to obtain 2030 SDGs.

\section{Limitations}

The main limitation of this study is that it cannot account for the quality variation of SBA across regions of the country and how SES effects on the quality of SBA. This is an important question for further research. In addition, the small sample size of our dataset does not allow us to estimate the dynamic effects of IMR overtime on itself, ie, including IMR in previous years as additional explanatory variables in the SEM. The same kind of limit is applied to other variables. For instance, the impacts of SES, medical interventions, and population growth on IMR might last several years and at different magnitudes.

Ethical issues

This study used secondary data that have been published by Vietnam GSO and Vietnam's MoH, Hanoi, Vietnam. The data did not cover any individuals and their personal health status.

\section{Competing interests}

Authors declare that they have no competing interests.

Authors' contributions

MPN and CMN contributed equally to the paper's design and writing.

\section{Authors' affiliations}

${ }^{1}$ Department of Medical Services Administration, Ministry of Health, Hanoi, Vietnam. ${ }^{2}$ Queensland University of Technology, Brisbane, QLD, Australia. ${ }^{3}$ School of Nursing, Indiana University, Bloomington, IN, USA.

\section{Supplementary files}

Supplementary file 1. Goodness of Fit of the Random Effect Model.

Supplementary file 2. Goodness of Fit of the SEM.

\section{References}

1. General Statistics Office. Statistics Yearbook. 2005-2017. https://gso.gov. vn/Default.aspx?tabid=706\&ltemID=13412. Accessed January 2019.

2. World Health Organization (WHO). Definition of Skilled Health Personnel Providing Care During Childbirth: The 2018 Joint Statement by WHO, UNFPA, UNICEF, ICM, ICN, FIGO, IPA. WHO; 2018.

3. Vietnam Ministry of Health. National Plan of Action for Child Survival 2009-2015. Hanoi: Vietnam Ministry of Health; 2009

4. Vietnam Ministry of Health. Health Statistics Yearbook. Hanoi: Vietnam Ministry of Health; 2005-2015.

5. Socialist Republic of Vietnam. 15 Years Achieving the Vietnam Millennium Development Goals. Vietnam: Socialist Republic of Vietnam; 2015.

6. Do M. Utilization of skilled birth attendants in public and private sectors in Vietnam. J Biosoc Sci. 2009;41(3):289-308. doi:10.1017/ s0021932009003320

7. Chuong NC, Van Minh H, Thi Thuy Duong D, Duc DM, Anh Dao LT, Duy Anh N. Progress on maternal health care in Vietnam: findings from Vietnam Multiple Indicator Cluster Survey 2000, 2006, 2011, and 2014. Health Care Women Int. 2018;39(4):368-376. doi:10.1080/07399332.20 17.1405960

8. Målqvist $\mathrm{M}$, Lincetto $\mathrm{O}, \mathrm{Du} \mathrm{NH}$, Burgess $\mathrm{C}$, Hoa DT. Maternal health care utilization in Vietnam: increasing ethnic inequity. Bull World Health Organ. 2013;91(4):254-261. doi:10.2471/blt.12.112425

9. Lee HY, Van Do D, Choi S, Trinh OT, To KG. Trends and determinants of infant and under-five childhood mortality in Vietnam, 1986-2011. Glob Health Action. 2016;9:29312. doi:10.3402/gha.v9.29312

10. UNICEF. SDGs and Children in Vietnam. Hanoi, Vietnam: UNICEF; 2018.

11. O'Hare B, Makuta I, Chiwaula L, Bar-Zeev N. Income and child mortality in developing countries: a systematic review and meta-analysis. $J R$ Soc Med. 2013;106(10):408-414.

12. Brownell M, Enns J. Reducing child mortality in high-income countries: where to from here? Lancet. 2018;391(10134):1968-1969. doi:10.1016/ s0140-6736(18)30938-3

13. Pritchard C, Keen S. Child mortality and poverty in three world regions (the West, Asia and Sub-Saharan Africa) 1988-2010: evidence of relative intra-regional neglect? Scand J Public Health. 2016;44(8):734-741. doi:10.1177/1403494816675550

14. Badiani R, Baulch B, Brandt L, et al. 2012 Vietnam Poverty Assessment: Well Begun, Not Yet Done - Vietnam's Remarkable Progress on Poverty Reduction and the Emerging Challenges. 2013. http://documents. worldbank.org/curated/en/563561468329654096/2012-Vietnam-povertyassessment-well-begun-not-yet-done-Vietnams-remarkable-progress-onpoverty-reduction-and-the-emerging-challenges. Published 2013.

15. StatSoft Inc. Electronic Statistics Textbook. http://www.statsoft.com/ Textbook/Structural-Equation-Modeling. Accessed July 20, 2019. Published 2013

16. Kline RB. Principles and Practice of Structural Equation Modeling. 4th ed. New York: The Guilford Press; 2016.

17. Hooper D, Coughlan J, Mullen MR. Structural equation modelling: 
guidelines for determining model fit. Elecron $J$ Bus Res Methods. 2008;6(1):53-60.

18. Idrovo AJ. Three criteria for ecological fallacy. Environ Health Perspect. 2011;119(8):A332. doi:10.1289/ehp.1103768

19. Say L, Raine R. A systematic review of inequalities in the use of maternal health care in developing countries: examining the scale of the problem and the importance of context. Bull World Health Organ. 2007;85(10):812819. doi:10.2471/blt.06.035659

20. Gill CJ, Phiri-Mazala G, Guerina NG, et al. Effect of training traditional birth attendants on neonatal mortality (Lufwanyama Neonatal Survival Project): randomised controlled study. BMJ. 2011;342:d346. doi:10.1136/ bmj.d346

21. Houweling TA, Caspar AE, Looman WN, Mackenbach JP. Determinants of under-5 mortality among the poor and the rich: a cross-national analysis of 43 developing countries. Int J Epidemiol. 2005;34(6):12571265. doi:10.1093/ije/dyi190

22. Gebretsadik S, Gabreyohannes E. Determinants of under-five mortality in high mortality regions of Ethiopia: an analysis of the 2011 Ethiopia Demographic and Health Survey data. Int J Popul Res. 2016; 2016:1602761. doi:10.1155/2016/1602761

23. Department of Economic and Social Affairs, Population Division. World Mortality Report 2015. United Nations; 2017.

24. Afulani PA, Moyer C. Explaining disparities in use of skilled birth attendants in developing countries: a conceptual framework. PLoS One. 2016;11(4):e0154110. doi:10.1371/journal.pone.0154110
25. World Health Organization. Human Resources for Health, Country Profiles: Vietnam. Manila: WHO Regional Office for the Western Pacific; 2016.

26. Singh K, Brodish P, Suchindran C. A regional multilevel analysis: can skilled birth attendants uniformly decrease neonatal mortality? Matern Child Health J. 2014;18(1):242-249. doi:10.1007/s10995-013-1260-7

27. Say L, Raine R. A systematic review of inequalities in the use of maternal health care in developing countries: examining the scale of the problem and the importance of context. Bull World Health Organ. 2007;85(10):812819. doi:10.2471/blt.06.035659

28. United Nations Population Fund (UNFPA). Reaching Out to Minorities in Viet Nam with Midwives who Speak their Language. UNFPA; 2010.

29. McGovern ME, Canning D. Vaccination and all-cause child mortality from 1985 to 2011: global evidence from the Demographic and Health Surveys. Am J Epidemiol. 2015;182(9):791-798. doi:10.1093/aje/kwv125

30. Breiman RF, Streatfield PK, Phelan M, Shifa N, Rashid M, Yunus M. Effect of infant immunisation on childhood mortality in rural Bangladesh: analysis of health and demographic surveillance data. Lancet. 2004; 364(9452):2204-2211. doi:10.1016/s0140-6736(04)17593-4

31. National Institute of Hygiene and Epidemiology (NIHE). Achievements of Expand Program Immunization 2011. http://tiemchungmorong.vn/vi/ content/lich-su-tcmr.html. Accessed July 27, 2019. Published 2011.

32. John TJ, Samuel R. Herd immunity and herd effect: new insights and definitions. Eur J Epidemiol. 2000;16(7):601-606. doi:10.1023/a:1007626510002 